\title{
China Model: What Can Africa Learn from China's Path?
}

\author{
Biniam Mekru Alemayehu \\ International Business school \\ Yunnan University of finance and Economics \\ Kunming, China \\ biniammekru@hotmail.com
}

\begin{abstract}
Africa and China have several similarities; both have a long history with beautiful cultures and traditions. Furthermore, they passed through misfortune periods. Besides, the continent of Africa \& china had almost similar economic status before 50 or 60 years. But now their difference is very huge, China recorded marvelous economic development, which is shaking the all world and disproving the neoliberals "The End of History" delirium and become the second largest economy in the world but Africa, even though there are very few developing countries are there, is still in the darkest age. The main questions here is, how this gap is created? To answer this question and find out a lesson for African's stagnated economy, to give life from the China model, we are forced to looking back the two the last 40 years history and path.
\end{abstract}

When we look at the Chinese model, above all there is one important element is there, "innovation based on inheritance, which means to create something new out of the old". In all perspectives the Chinese use this guideline for articulating their economic and political path [1]. But most of African's are still controlled by corrupted leaders and using a pre-scribed policy, privatization and market liberalization that is benefitting few, which is cooked by the previous colonizers and has been walking in the darkest room and couldn't find the door, which leads to light. So, what African's should learn from Chinese model for solving its problems are, looking back to its own history and make the economic and political policies based on Africans organic elements and start to fight corruption, as the Chinese president Xi Jinping said both its symptoms and root causes.

Key words-China's model; pre-scribed policy; lesson for Africa; corruption

\section{INTRODUCTION}

Africa had a long history of civilization; the continent had a trade relation with many parts of the world including with china. But through time, the continent become fragmented and failed under the colonized powers. All African nations except Ethiopia and Liberia were under colonized rules for many decades. But after many years of struggle for independence, majority of African countries were freed from colonization at the end of 1960s.In general the continent counts around 60 independent years. But after those 6 decades, Africa, even though there are some economic difference among the African states but for this article the author prefers to use Africa as a content to represents majority of the states, is still in darkest age for their people, its economy is stagnated, war and conflicts are a unique characteristic for the continent and rampant corruption is deep rooted. According to Africa Check October 2012 report, ever year millions of Africans are dying through war, conflict, starvation, diseases and so on. But more than \$ 148 billion lost from Africa annually through corruption. Even though the continent has an estimation of trillions of Dollars from natural resources, still lend its hand for loan and aid. This fact is a painful tragedy for Africans.

When we look at China, as the same way to Africa, it has a long-time history and tradition and had a misfortune time like Africa, especially starting from the first opium war (1840) up to the new birth of China in 1949, this big nation reduced to being a semi-colonial and semi-feudal country [2]. To get its new birth the Chinese people sacrificed their human and material resources. But since 1949, people republic of China was established, the country history started to change and specially after the opening up policy was launched at 1978, China recorded unforgettable economic growth and catch up the second ladder on the economic growth record. Out of many marvelous achievements, China GDP became \$11.2 trillion in 2016 and 700 million citizens have risen above absolute poverty from 1979 - 2016 and changes the life of their people and its nation [3].

A question for how China Change its history and why Africa is still living in the dark age, and what are the lessons Africa should learn from the China model should be answered. So, the aim and objectives of this article is finding out those answers.

This article has 3 parts, the first part is about the historical relationship between Africa and China, in the second part the writer tries to show the China model and Africans major problems with its solution, based on the lessons from China's path. Finally, there will be a conclusion and recommendations.

\section{POLITICAL AND ECONOMIC BACKGROUND OF CHINA AND AFRICA}

\section{A. China-Africa Relationship}

The relationship between China and Africa has a history of thousand years. As back as the second century BC, during the Han dynasty (206 BC - AD 220), there was indirect trade of precious goods between the two. And the invention of the compass in the Song dynasty (960 - 1279), led to a significant expansion in Chinese navigation, and rapidly advanced exchanges between china and Africa both in people and products. Direct association between china and Africa continued at the Yuan dynasty $(1279$ - 1368) and at the Ming dynasty (1368 - 1644). But when Africa darkest period came, at the 15 th century, when western colonialists invaded Africa and from the mid-19th century with the invasions of western powers, China was reduced to a semi-colonial nation, and then the relationships between China and the continent of Africa got an obstacle. After the 1880 s, hundreds and thousands of Chinese people were press-ganged to Africa, to build railways 
and work on mines or farms. The Dakar railway in western Africa, the Congo Railway in central Africa and gold mines in south Africa were soaked with Chinese blood. Similar misfortunes brought Chinese and African nations together [4].

At the time of African nation struggle for independence, China helped both in material and moral support. After the Birth of new china and independency of African nations the two-relationship become strong. When we see the economic support of China to Africa from 1956 - 2005, there are 900 projects was implemented for 53 African nations [4], and the other data indicate that from 2000 - 2011, there were 1673 projects were built in sub Saharan African countries and a $\$ 75$ billion in commitment of official finance [5], and China canceled billions of dollars debt of African countries [6]. China has built an excellent Diplomatic relation with all African nations, the African union head quarter building(Africa Union conference center and office complex), in Addis Ababa Ethiopia, was fully funded and built by Chinese government and hand over to Africa union at 2011, the other is Africa CDC, center for disease and prevention for safeguarding African's Health, starting to build by Chinese, this project head quarter will build in Addis Ababa, Ethiopia and the other five regional center's will also built in different African nations.

China and Africa, in terms of technology transfer, there are many Chinese companies in Africa for investing on fields such as Construction, mining, information technology and so on. Therefore, the advent of these kinds of companies paved the way for Africa to enhance their technology capacity and human capital. China also supporting the African's human power through training and scholarship program, Ministry of education of people republic of China 2016 data showed that in 2015, 66,746 African students enrolled in china for first, second and third-degree program. This program has been building a strong relationship between the new generation of Africa with china.

\section{B. Comparing China's and African's Economic Achievements and Current Situation}

China and Africa had many similarities in the 1950,1960 and 1970s, both economy was based on agriculture, majority of their people lived in rural areas, poverty level was very high and deep rooted. In 1978, out of china population $82.6 \%$ was lived in rural areas and the majority was in absolute poverty line [3], and Africa around $85-95 \%$ of population was live in rural areas, under deep rooted poverty on the same period. The population of china is 1.38 billion and Sub- Saharan Africa 1.03 billion in 2016. (The world bank data, 2018)

But after four decades later China and Africa as a continent gab become enormous, China annual growth of GDP from 1979-2015, is $9-10 \%$, but Africa Annual GDP growth in 1990(2.4\%), 2007(7.1\%) and 2016(1.2\%). The total GDP of China reached \$ 11.2 trillion in 2016 , which is the second largest economy in the world from $\$ 153$ billion at 1976 [3], but Africa only \$ 1.5 trillion in 2016 from \$ 308.7 billion in 1990 (The world bank data, 2018). China Per capital income reached \$ 8123 in 2016 from \$ 165.4 at 1976 but Africa is still $\$ 1464$ in 2016 . China import export volume become \$ 3.66 trillion, the world largest in 2016 from $\$ 13.4$ billion which was $5 \%$ of the U.S volume [3], but Africa \$ 334 billion in 2016 from $\$ 78$ billion in 1990. China foreign exchange reserve become $\$ 3.01$ trillion, which is world NO.1, but the median level of government debt in sub-Saharan Africa will probably rise to more than 50 percent of gross domestic product in 2017, IMF says [7].
In China 700 million citizen have risen above absolute poverty from $1979-2015 / 16$,it implies that $70 \%$ of the world poverty eradication occurred in china [8], but in Africa, people live in under poverty line(less than $\$ 1.9$ a day) increase in number from 301 million in 1993 to 400 million in 2013 and the number of undernourished people in sub Saharan Africa has increasing from 200 million $(20.8 \%)$ in 2015 to 224 million $(22.7 \%)$ in 2016 mainly due to the impact of conflict and climate change (FAO report in Nov,2017,) In sub-Saharan Africa 1 in 3 adults can't read, 48 million youths (age 15-24) are illiterate, $22 \%$ of primary aged children are not in school and total literacy rate reached to $59 \%$ [9]

The above data and information showed that China recorded the fastest economic growth in the last 40 years and become the second largest economy in the world and also has completed the transformation from an agricultural to a manufacturing country with urbanization rate of $57 \%$. But Africa dept is rising every year and during $2011-2013$, the external dept stock amounted on average to $\$ 443$ billion, compared with $\$ 303$ billion in 2006 - 2009, in the other way round it is estimated that financing the sustainable development goals in Africa could require investment of between $\$ 600$ billion to $\$ 1.2$ trillion per year and $\$ 93$ billion only for infrastructure but Africa can only raise half of this amount[10].Therefore, bluntly speaking African economy is stagnated! The question is why? The author shall try to answer this question in the next topics.

\section{The Political Structure Difference between China and African}

Many Chinese scholars agreed that one of the key factor for China's economic miracle is, not liberalized the political system of the country, rather China has been using their own way of democracy and governmental structure. But almost all African nations after independency has been following the western model, which doesn't solve African genetic problems, not bring democracy and economic development rather it rises the suffering of African people because it is a pre-scribed model, which is copy and implement the western political structure without looking the continent background and current states. So, the basic difference between the two is, china uses a political system which is its own history and tradition based [8], whereas Africa reject its own indigenous system and just copy and paste the western model.

\section{HOW DID CHINA GROW? AND WHAT CAN AFRICA LEARN FROM CHINA'S PATH?}

\section{A. China's Political Structure for Adopting African's Organic Democratic System}

China is a civilizational state and the communist party of china is a continuation of china's long tradition of a unified Confucian ruling entity [8]. Specially after the founding of people republic of China in 1949, China started to follow its own path by rejecting the political liberalization policy and after many ups and downs China started to follow socialism with Chinese characteristic path since 1978. When we see the basic characteristics of china's political system, in the one hand it is mass based democracy, in the grass root at the villager's there are more than 640,000 and at the residents' committees and grass roots self-governs in urban areas there are 70,000 citizens are participating in many decision making activities. At the higher level there is CHINESE PEOPLE'S POLITICAL CONSULTATIVE CONFRENCE (CPPCC) which including the China communist party(CPC), the eight democratic parties, democratic personages with no party 
affiliation, various ethnic minorities, Compatriots from Taiwan, Hongkong and Macao, returned overseas Chinese and special invited individuals. The CPPCC participating in political consultation, democratic supervision and participation in the deliberation and administration of the state affairs. Besides when the state is to adopt major policies or decide on major issues concerning the national economy and people's livelihood, the CPC as a ruling party will first consult with various ethnic groups, political parties, people's organizations(there are around 12 and it is like a bond between the $\mathrm{CPC}$ with the masses) and democratic personages with no party affiliation to reach common understanding through conferences, forums and briefings before final decisions are made[11].

In the other hand there are multi party cooperation and political consultation between the CPC as a leading position and the eight fellow democratic parties. Those parties are also participating in governess of the country and participate in consultation and decision making concerning major political and major issues in people's life. And in the inside of CPC there are also different organs which keep the party from nepotism, corruption and undemocratic elements and so on [11].

To summaries the Chinese political system, it is not copy from anyone but it is an "innovation based on inheritance, which means creating something new out of the old" [1]. In addition to this it is a democratic system in the bases of democratic substance (even based on Abraham Lincoln famous principle of democracy, A government of the people, by the people, for the people) but not by western democratic structure [8].

When we see the African case, one of the key factors that hold back African economy is its copy and paste political structure and in most of African nation power is concentrated in to one or a few group of people. Most of the time a concentrated power is more likely become corrupted, but in Africa it is not more likely, it is clear. So, African political structure is not suitable for liberating its people from mental and financial poverty rather it is more appropriate for those greedy and corrupted leaders. This system in most of African nations excluded the majority and benefits the small one, that is why it breeds in many nations war and conflict.

When we look back to African's history and tradition, there were several democratic cultural organs in villages, towns and others which people call together, discuss their problems, debating in some issues and make decisions based on consensuses [12]. This supposed to be a root for African democracy and good government. But after independency African leaders separates the roots from the tree and trying to give artificial life for the tree. But it doesn't work since in $1960 / 70$ s up to now. So, the solution is put the root and the tree together, which means connect the African people with their own traditional and cultural democratic system. In this system power is not concentrated in one or few persons rather it is dispersed among the masses. In such kinds of system there is no huge space for corruption, nepotism and undemocratic activities. To make these real, African leaders should start thinking out of the box and looking forward their own and their children future fate. If it is say so, the question for how to articulate and implement such kinds of system in Africa will get a clear answer. This is what Africans should learn from Chinese experience. This is what an innovation based on inheritance means for African case.

\section{B. China's Economic Model for Establishing Context Based African Economic Structure}

Looking back at history, one important factor that has contributed to the continuation of the Chinese civilization is innovation based on inheritance, which means to create something new out of the old [12]. Before 1949, China tried to follow the western practice, but failed. And then from $1949-$ 1959, it mainly followed the soviet practice, but the living standard of the people was improved very slowly. After 1978, Deng Xiaoping put forward the theory of building socialism with Chinese characteristics. "We can say this is a new path that has never been taken by anyone before and we have made it" [13]. The socialist road with Chinese characteristics started in 1978 , When the third plenary session of the 11th central committee of the CPC was convened. At the meeting, Deng Xiaoping made a speech entitled "Emancipate the minds, seek the truth from facts and unit as one in looking to the future", in which he said "First liberate your thinking. If a party, a country or a nation starts everything from books, with rigid thinking and blind worship, it will not able to move forward, its life will terminate and it will perish [1]. This theory grows in to the concept of "scientific outlook on development" proposed by Chinese leader Hu Jintao. It also means that China should pay attention not only to the growth rate of the gross domestic product, but also to progress of society as a whole and to the sustainability of development [13].

In Chinese economic model, the government is for the people and guides the people forward in economic, cultural, scientific and technological advancement and the ruling party should represent the fundamental interests of the broadest masses of the people, the countries development proceeds from people's needs and adheres to a comprehensive, coordinated and sustainable path, which is called the "Scientific outlook on development "and it is a prudent approach is combined with bold experiments and all the major reforms are first tried in certain areas before they are popularized [13]. "The three basic characteristics of the China model are: endogenous, innovation and gradual. The basic difference between the western model and china's model is their values of development: the goal of the former is to help the minority, while the goal of the latter is to help ordinary people. The China model is a process of gradual reform strategy, the self-generated innovation of economic system and mechanism is a gradual process. This means there is no example we can copy. What we have is only the wisdom of Chinese people. Since there is no model that we could imitate, or any ready theory to guide our reform, we could only cross the river by touching the stones under water" [14].

The whole reform process started with the countryside, with agriculture, and then industry, and then commerce. It started with coastal areas, and then the interior parts of China. The same with the Belt and Road initiative: we have the idea of what we call the "key projects," or "pivotal projects," and "pivotal countries." It's not all the countries simultaneously, we have conditions that differ from one to another. Some countries have more mature conditions, so we do it first and then try to have what we call the demonstration effect, to show others, so others can decide to follow or not. So, there is a "sense of priorities and sequences" [8].

As president Xi Jinping said, "socialism with Chinese characteristics has crossed the threshold in to a new era making history juncture in china's development". Now china's model is not a theory but is pass through practiced and shows its success and it's disproves the Francis Fukuyama's End of history by "the end of end of history" [8]. 
But in the Africa case, the reality is that neoliberal globalization builds the growth and development of one part of the world at the expense of other parts. That is done through the trajectories of a global free market. Globalization has engendered poverty and inequality to Africa due to the continent's uneven incorporation into the world capitalist economy [15]. Reforms in Africa have been much more directly influenced by external theoretical paradigms and policy strategies. The macroeconomic and sector reforms of the 1980s and 1990s were shaped by the World Bank and International Monetary Fund structural adjustment programs, based on the neoliberal economic paradigm. But the reform in Africa didn't manage to achieve their main goal of high rates of growth and did little to alleviate poverty [16]. It implies that, in most African nations the economic system is not give major emphases for traditional and informal sector, which holds majority of the people.

The current situation of Africa, which stated in the above titles, supports those article writers' ideas. African economy in real terms doesn't benefited from the "shock therapy" economic liberalization policy which was imposed by the western countries and institution, rather Africa losses a lot of economic advantageous through a competition which a winner is known before the race started. Data's and facts which I mentioned in the above indicate that African economy in the last more than 50 years not growing rather it stagnated.

One of the main factors which brings many distractions in to Africa is the pre-scribed economic policies, privatization and market liberalization that benefits few, which has been swallowing by African's without testing the bitter test of it. So, African leaders should look in to inside and share the people woe and make themselves ready for real change. The solution for this economic and humanitarian devastation will be found in the African's own indigenous economic path, that focuses on traditional and informal economic sector which encompasses the masses. Again, this is what an innovation based on inheritance means for African economic case.

\section{What Africa should Learn from China in Fighting Against Corruption?}

President Xi Jinping said, "no one is immune, not even communist party leader who once seemed untouchable", and "it was explicitly stated that both symptoms and root causes of corruption should be addresses, with education as the basis, laws as the guarantee and supervision as the key, and the soil that breeds corruption should be continuously removed through deepening reform". The above statement of the president has been proven by practical actions, in 2015 china was punished more than 300,000 officials from light up to arrest punishment.

Corruption is a threat especially for a country which has a state intervention in the economy. Chinese knew this very well and have been fighting it without any hesitation, they have strong political commitment and practical engagement in fighting corruption and their footsteps indicate that they don't joke on this issue. This is another mystery behind their miracles development.

When we look at the African situation, it needs continued continent-wide cooperation, and engagement and support from international organizations and their members in tackling illicit financial flows and debt relief. This is crucial, as Africa lost about $\$ 854$ billion in such flows from 1970 to 2008 . This sum is nearly equivalent to all official development assistance received during that period and only one third would have been sufficient to cover its external debt [10].
The 2012 African Union (AU) report on corruption has revealed that more than $\$ 148$ billion is lost due to corruption in Africa every year. To compare, developed countries gave $\$ 22.5$ billion in aid in sub Saharan African in 2008. African poverty alleviation programs are regularly affected by corruption. In the other side of the coin infrastructure is a basic element for development and for eradicate poverty, Africa needs $\$ 93$ billion every year only for infrastructure, but the continent couldn't cover even half of it rather its losses $\$ 148$ billion annually. This is painful!

Corruption has a direct relationship with poverty, conflict and war. Corruption control is the best governance tool in the battel against conflict, violence and crime. As a policy implication, our result broadly indicates that, the waves of conflicts and crime in African continent could be addressed to a certain extent if the fight against corruption is taken seriously by governments of sampled countries. Such corruption-control efforts will go a long way not only to improving the quality of life and well-being of citizens conditions for sustainable economic growth. Ultimately, the measure will prevent organized criminal groups from corrupting, colluding with and /or penetrating state structures [17].

In Most of African countries, political power is a tool for accumulate wealth. Some scholar uses the word "patrimonial" system, which means individual or few groups use government office for personal use and for accumulation of wealth. This type of political system represents many African states [17] In this system the nation is not only loss its wealth but also the working and creativity potential of its people. In most places most of the ordinary people perceive and believe that, controlling state power is like a privilege to be one of the richest person in that given country without his/her own effort. That is why conflict and war becoming the unique characteristics of African continent. Therefore, the African nations and people should build a strong institution and work with it for fighting corruption without any hesitation, as Chinese president Xi Jinping said, "it was explicitly stated that both symptoms and root causes of corruption should be addresses, with education as the basis, lows as the guarantee and supervision as the key, and the soil that breeds corruption should be continuously removed through deepening reform". Without this African development and eradicating poverty never be realized and peace will be far from the continent like heavens apart from earth. So, African states should focus on the establishment of strong and open institutions to combat corruption. This is the other lesson, Africa should and must learn from Chinese.

\section{Reducing Conflict and Promoting Peace}

African development is substantially being retarded by consistent waves of crimes and conflicts. The institutional environment in Africa over the past decades has been seriously plagued by violence, crimes and conflicts. One of the reasons advanced for this plethora of conflict is the absence of good governance, with corruption assuming central stage [18]. And from 1990 - 2014 there were about 400 conflicts and wars are recorded [18]. In most of African nations state power used for accumulation of wealth rather than benefiting the masses, because of this majority of the people become marginalized and excluding from the economic benefit, this leads to conflict and war. Even though those which seem peaceful nations, as long as this problem is continuing, predicting the conflict couldn't need any special skill. In the other side of the coin conflict and war has a direct impact on development, that is why African poverty mark is increasing 
and in general African economy is stagnated. Realizing sustainable peace and security is the direct result of having good governance and giving attention to the public's justifiable demands. Violent conflict has turned Africa in to a continent of refugees and displaced persons. About six million of the world's estimated refugee population of seventeen million is in Africa and approximately 15 million of the 25 million internally displaced persons world-wide are Africans.

Africa is the richest continent of the world with natural resources. But this resource has not been useful for saving its people lives from not dying by hanger rather it's escalating the level of conflict and war. In many African countries still now, people are dying in the ground through diseases, starvation, war and conflict but billions and trillions dollar amount of natural resources are laying in the underground. Democratic republic of Congo(DRC) is a best example to show this tragedy, DRC budget deficit increasing from 6.3\% in 2011 to $11 \%$ in 2013 , in $201170 \%$ of the country youth(aged 15-24) have no job, $70 \%$ of Congolese live on less than $\$ 1$ a day, $75 \%$ of the nation's people suffer from food security, 53\% of the population have no access to drinking water and only $9 \%$ have access to electricity [19] and from 1998 - 2008 period more than 5 million people dead through war in conflict(IRC 2008). But Congo's(DRC) natural resources estimated more than 20 trillion dollars [19] which is much higher than USA total GDP (\$ 18.5 trillion) or we can put it like it is more than the total GDP of EU area (14.1 trillion) + Japan total GDP (\$6.2 trillion). The causes of this tragedy are conflict and war, which is erupted because of corruption and luck of good governance. This is the bitter truth and facts about African conflict and war.

The African leaders and people should understand this tragedy and must start to feel this pain, if Africans leader really think for their own people it is easy to solve its own internal conflicts and between nations problems, without any foreigners help. But the question is, are Africans ready to choose the right chose? China's miracles economic growth never been inconceivable without peace and harmony among the people of China. So, the use and benefit of peace is the other lesson which Africa supposed to be learned from china.

\section{E. Economic and Political Integration in Africa and the Promoting of African Unity}

"Our objective is African union now. There is no time to waste. We must unite now or perish. The resources are there. It is for us to marshal them in the active service of our people. Unless we do this by our concerted efforts, within the framework of our combined planning, we shall not progress at the tempo demanded by today's events and the mood our people.” Kwame Nkrumah's speech (1963). After more than 5 decades Africa is still in chaos, as Nkrumah's predicted.

The unity of Africa has tremendous benefits, When Africa unites, it will be able to pool its investment resources to ensure that it will have enough money to invest in the large-scale production of industrial and agricultural goods and services, only a united Africa, with its more than one billion people, can provide the requisite market size to stimulate large-scale production, Only a united Africa will be able to protect its market!, The balkanized states of Africa are always at a disadvantage when, separately, bargaining with the stronger industrial nations of Europe, Asia, and North America [20].

One of the key factors for China's development is the unity of the 1.4 billion people with 56 ethnic groups. They always give priority for their unity because it is the source of their strength. I think China is the best example for Africa to show the marvelous use of unity.

\section{F. The Importance of African's Research and Development Institution}

Experimentation helped reduce risks and improved the success rate of reforms through scaled up implementation of effective pilot projects and elimination of unsuccessful policy options that could have potentially had disastrous spillover effects. Chinese political leadership was supported in these reforms by the evidence and guidance of research institutions such as the China Development Research Group, the Chinese Academy of Social Sciences, and the Development Research Center of the State council [16]. In the same way research and development institution is very important for African development because most of African nations, policies and strategies are a copy paste from the other corner of the world, besides its institution lack the capacity of implements policies and strategies, and also there is a gap between the policy makers and implementers. Those problems will be solved through African's own research and development institution. As I mentioned above the basic element, Africa should learn from Chinese is "an innovation based on inheritance", to make it this real the use of African's research and development institution is very essential.

All African nations should work together to build African research and development institution, that will articulate continent-wide economic and political policies and strategies which should be based on its own core values, history, tradition and culture. This institution should be a source of economic skill for the African leaders. So, especially for this institution the African Elites and diasporas should contribute their level share for their own mother land.

\section{CONCLUSION AND RECOMMENDATION}

\section{A. Conclusion}

Africa is a continent which has a civilized background, a long history, own tradition, culture and the wealthiest landmass on the face of the earth. However, it is the only continent of the world that development proving to be intangible. But why? The answer is clear, incompatible political and economic policy, disunity, use state power for personal benefit and for accumulation of wealth, war and conflict, rampant corruption and lack of strong institutions. Though those are symptoms, the real disease is lack of African's history, culture and tradition based political and economic path, which breed all the above problems. So, the root cause of African problem is African's itself, not anyone, as the same way the solution for all problem is found in the hands of the African government and people, that is looking back to its origin and connect the tree with its root, which means connect the African people with their own indigenous political and economic system.

The other issue is the continent should start looking internally and stop blaming others for its own problems, there is no one who should care and responsible than the African's itself, for those African's children which is dying everyday through war, conflict and starvation. So, the African leaders must start to feel this pain and start to use the public office for the benefit of the masses. Those are the only ways for African's development becoming tangible.

\section{B. Recommendation}

The writer didn't say Africa needs to copy and paste the Chinese model because he doesn't want to repeat the mistakes; 
rather there are a lot of experiences which Africa should learn from it. One of the key element for African lesson from the china model is, an idea of innovation based on inheritance, which means to create something new out of the old. So, Africa should back to its origin and think and plan based on the organic material.

As Dr Abiy Ahemed, the new Ethiopian prime minister, said African's leader should start to think like, their nation is not inherited from their parents, to do whatever they like, rather they borrow it from their own children. So, the African leader should keep the nation properly and add value on it for the coming generation.

Africa, after independency, is now a 60 years old man age. So, it should choose the right chose as an old man, which hopefully think carefully to choose the right chose, that will benefit his children and the coming generation. But I have a question here for all Africans. Will Africa take that choice?

\section{ACKNOWLEDGEMENT}

On the completion of the paper, I would like to express deepest gratitude to all those kindness and advice have made this paper possible.

\section{REFERENCES}

[1] X. Ren. The Chinese Dream: What it Means for China and the Rest of the World. Cengage Learning.2017.

[2] B. Jin. Understanding China. China intercontinental press.2008.

[3] www.chinatoday.com.cn

[4] W. Yuan, W., 2006. China and Africa 1956-2006.

[5] A. M. Strange, B. Park, M J. Tierney, A. Fuchs, A. Dreher, and V. Ramachandran, China's development finance to Africa: A media-based approach to data collection.2013.

[6] https://www.commondreams.org/newswire/2015/12/04/chinaannounces-debt-cancellation-african-summit

[7] https://www.bloomberg.com

[8] ]https://www.youtube.com/watch?v=P7XIYP0LvgI

[9] https://www.africanlibraryproject.org

[10] Economic Development in Africa Report 2016

[11] Z. Yin, The political system of China. China Intercontinental Press.2004.

[12] I. A. Kanu, AFRICAN TRADITIONAL DEMOCRACY.

[13] Q. Zhao, J. Naisbitt, and D. Naisbitt, A Dialogue between East and West, the China Model.2010.

[14] J. Jinquan, Study of the china model. Analysis of Economic Development path of China.2007.

[15] O. Kojo, Political Economy of Africa and the Contemporary Global Crisis: the dynamics of dominations and crisis. Conference paper.2012.

[16] Z. Chen, C. Hsu, and S. Fan, Steadying the ladder: China's agricultural and rural development engagement in Africa. China Agricultural Economic Review, 6(1), pp.2-20.2014.

[17] S. Asongu, S. and O. Kodila-Tedika, O., 2016. Fighting African conflicts and crimes: which governance tools matter?. International Journal of Social Economics, 43(5), pp.466-485.2016.

[18] http://africacenter.org/2014/09/

[19] AfDB, O.E.C.D. and UNDP, U., 2012. African Economic Outlook 2012. Country Note Burundi.

[20] www.aaprp-intl.org/article/10-reasons-why-africa-must 